OPEN ACCESS

Edited by:

Yu-Min Kuo,

National Cheng Kung University,

Taiwan

Reviewed by:

Abhay Sagare,

University of Southern California,

United States

Lee L. Rubin,

Harvard University, United States

*Correspondence:

Ken-ichi Mizutani

mizutani@pharm.kobegakuin.ac.jp

Received: 12 May 2020 Accepted: 01 September 2020 Published: 29 September 2020

Citation:

Watanabe C, Imaizumi T, Kawai $H$,

Suda K, Honma Y, Ichihashi M,

Ema M and Mizutani K-i (2020) Aging of the Vascular System and Neural Diseases.

Front. Aging Neurosci. 12:557384. doi: 10.3389/fnagi.2020.557384

\section{Aging of the Vascular System and Neural Diseases}

\author{
Chisato Watanabe ${ }^{1,2}$, Tsutomu Imaizumi ${ }^{3}$, Hiromi Kawai ${ }^{3}$, Kazuma Suda ${ }^{3}$, Yoichi Honma ${ }^{3}$, \\ Masamitsu Ichihashi ${ }^{1}$, Masatsugu Ema ${ }^{2,4}$ and Ken-ichi Mizutani ${ }^{1 *}$ \\ ${ }^{1}$ Laboratory of Stem Cell Biology, Graduate School of Pharmaceutical Sciences, Kobe Gakuin University, Kobe, Japan, \\ ${ }^{2}$ Department of Stem Cells and Human Disease Models, Research Center for Animal Life Science, Shiga University of \\ Medical Science, Shiga, Japan, ${ }^{3}$ Basic Research Development Division, Rohto Pharmaceutical Co., Ltd., Osaka, Japan, \\ ${ }^{4}$ Institute for the Advanced Study of Human Biology (ASHBi), Kyoto University Institute for Advanced Study, Kyoto, Japan
}

Vertebrates have acquired complex high-order functions facilitated by the dispersion of vascular and neural networks to every corner of the body. Blood vessels deliver oxygen and nutrients to all cells and provide essential transport systems for removing waste products. For these functions, tissue vascularization must be spatiotemporally appropriate. Recent studies revealed that blood vessels create a tissue-specific niche, thus attracting attention as biologically active sites for tissue development. Each capillary network is critical for maintaining proper brain function because age-related and disease-related impairment of cognitive function is associated with the loss or diminishment of brain capillaries. This review article highlights how structural and functional alterations in the brain vessels may change with age and neurogenerative diseases. Capillaries are also responsible for filtering toxic byproducts, providing an appropriate vascular environment for neuronal function. Accumulation of amyloid $\beta$ is a key event in Alzheimer's disease pathogenesis. Recent studies have focused on associations reported between Alzheimer's disease and vascular aging. Furthermore, the glymphatic system and meningeal lymphatic systems contribute to a functional unit for clearance of amyloid $\beta$ from the brain from the central nervous system into the cervical lymph nodes. This review article will also focus on recent advances in stem cell therapies that aim at repopulation or regeneration of a degenerating vascular system for neural diseases.

Keywords: vascular system, capillary vessels, neocortex, vascular aging, neural diseases

\section{INTRODUCTION}

The brain's vascular system is highly organized to efficiently deliver oxygen and glucose to its tissues. Anatomically, dense vascular networks of arteries and veins are found in the pia mater, whereas the parenchyma contains only capillaries. The basic structure of the blood vessels in the neocortex is the delivery of blood from the cortical surface by the pial vessels into the parenchyma perpendicularly by the periventricular vessels and drainage to the surface. Generally, arteries that supply blood to the brain branch into smaller arterioles, which eventually branch into the smallest blood vessels, known as capillaries. Capillaries carry oxygen and nutrients to the surrounding neural cells, and the capillary network is where the majority of the molecular exchange occurs between 


\section{Systematic Vascular plexus}

\section{Capillary abnormalities}

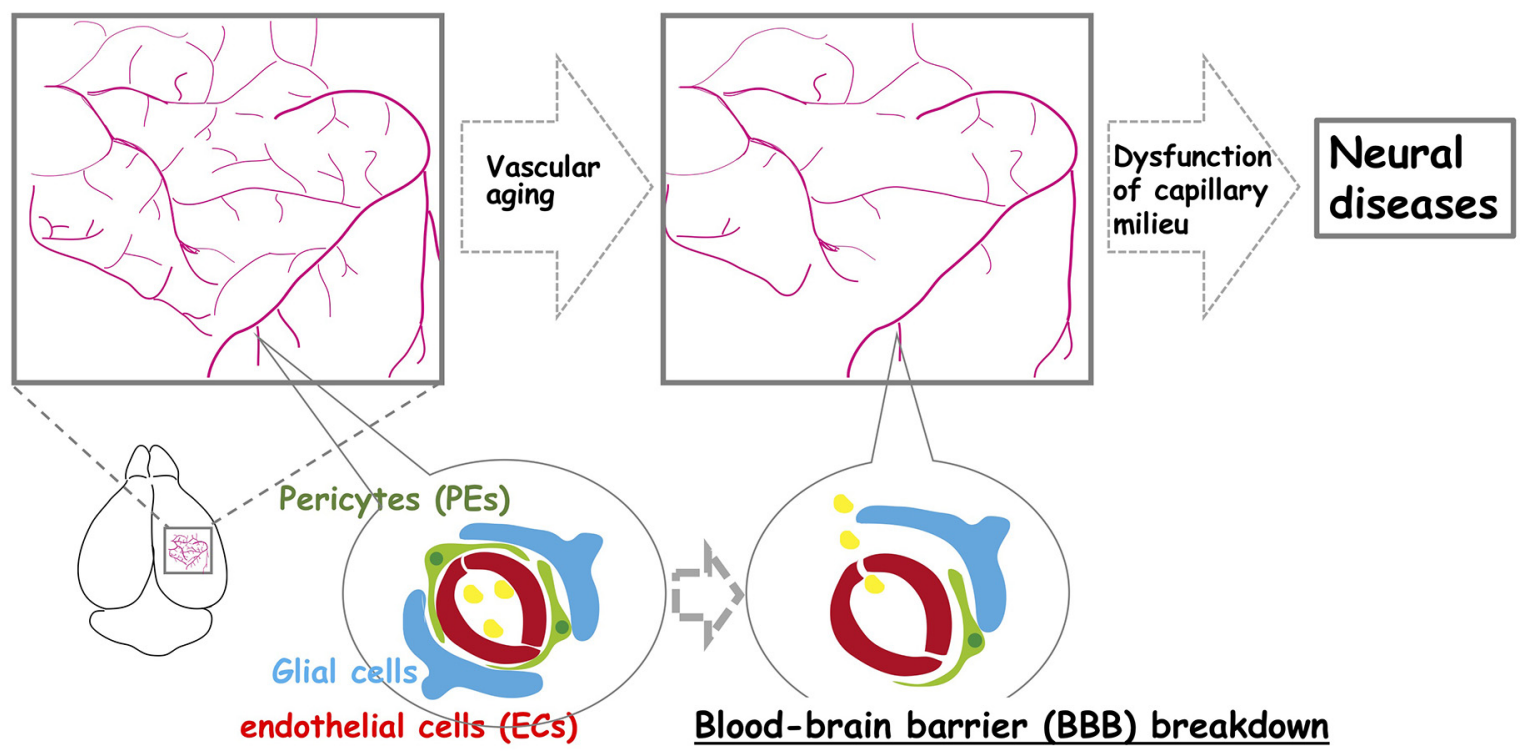

FIGURE 1 | The neocortex-specific capillary structure is constructed during development but is broken down with aging. The vascular network is constructed to create a spatiotemporal capillary milieu in the brain. However, age-related structural decline in the integrity of the vascular system including vascular rarefaction contributes to various neural diseases.

blood and tissue. A recent study showed that capillary endothelial cells (ECs) in the aged brain exhibit transcriptional change primarily, in comparison with arterial and venous cells (Chen et al., 2020).

What happens to the brain when blood vessels are lost? More than one hundred years ago, Osler (1898) stated, "A man is as old as his arteries". Tissues cannot survive without blood vessels to supply sufficient oxygen and nutrients. This is the case during embryonic development, for example, when the unfavorable distribution of vascular networks interferes with the normal development of organs. In contrast, brain vasculature undergoes many structural and functional alterations during aging (Figure 1). For example, capillary density declines (Klein and Michel, 1977; Wilkinson et al., 1981; Reeson et al., 2018), neovascularization potential attenuates (Frenkel-Denkberg et al., 1999; Rivard et al., 1999, 2000; Gao et al., 2009), plasmaderived circulatory cues become impaired (Villeda et al., 2011; Katsimpardi et al., 2014; Castellano et al., 2017), blood-brain barrier (BBB) permeability increases (Villeda et al., 2011; Lee P. et al., 2012), and the cerebral blood flow (CBF) decreases (Tarumi and Zhang, 2018). Also, recent studies suggest that structural and functional lymphatic vessels lining the dural sinuses drain macromolecules from the central nervous system (CNS) into the cervical lymph nodes (Aspelund et al., 2015; Louveau et al., 2015; Sun et al., 2018; Figure 2). Mixed pathologies of both Alzheimer's disease $(\mathrm{AD})$ and vascular abnormalities are the most common cause of clinical dementia in the elderly (Attems and Jellinger, 2014; Bennett et al., 2018; Sweeney et al., 2018a). Herein, we discuss these and also explore the recent advance of stem cell therapy that targets neovascularization during neural diseases.

\section{SYSTEMATIC VASCULAR PLEXUS IS CONSTRUCTED DURING NEOCORTICAL DEVELOPMENT AND MAINTAINED TO EXERT DIVERSE FUNCTIONS}

The neocortex is one of the most sophisticated brain tissues. It consists of a horizontal six-layered structure, separated by cellular subtypes and neuronal projections (Bayer and Altman, 1991). The mammalian brain possesses characteristic regions of neural stem and progenitor cells (NSPCs), including the ventricular zone (VZ), and the subventricular zone (SVZ), which lines the lateral ventricles. NSPCs proliferate and self-renew to give rise to neurons, glia, and oligodendrocytes for normal brain development. An appropriate balance between self-renewal and differentiation is crucial for stem cell functions to generate precise cellular diversity in the neocortex (Mizutani et al., 2007; Franco and Müller, 2013; Inoue et al., 2017). The specific microenvironment where these stem cells are localized, the so-called stem cell niche, regulates quiescence, activation, differentiation, and cell fate. Recent studies have shown that one of the prominent components of the regulatory niche is the vascular niche (Vasudevan et al., 2008; Won et al., 2013; Ottone et al., 2014; Bjornsson et al., 2015; Tan et al., 2016), which creates specialized microenvironments via physically direct contact (Tavazoie et al., 2008; Komabayashi-Suzuki et al., 2019) and secreted-soluble factors (Shen et al., 2004, 2008; Kokovay et al., 2010).

Blood vessels have a relatively simple structure consisting of ECs that are surrounded by a basal lamina and an 


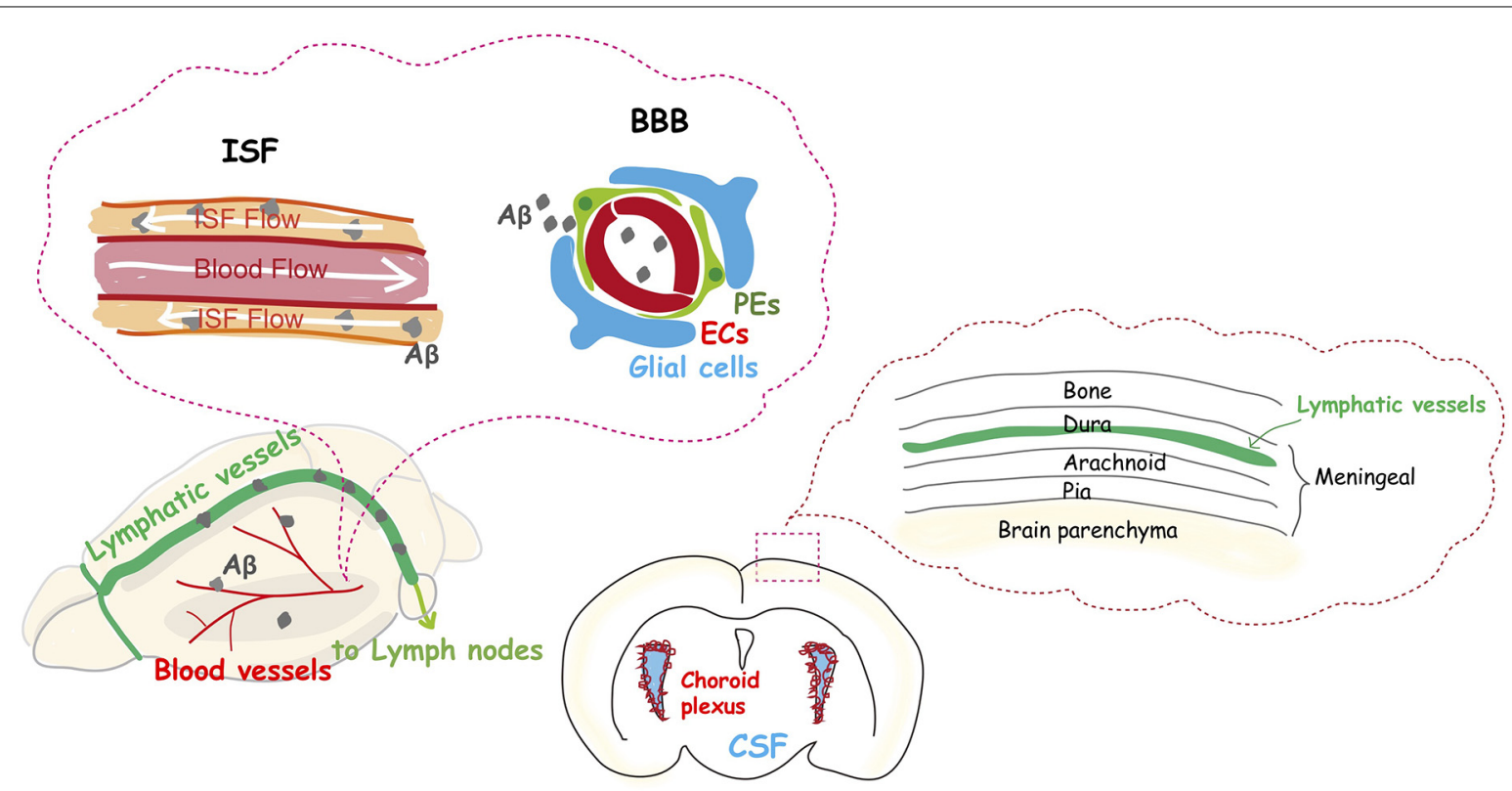

FIGURE 2 | The dysfunction of the vascular system is an integral part of Alzheimer's disease. The glymphatic system and meningeal lymphatic systems contribute to a functional unit for clearance of amyloid $\beta$ from the brain into the cervical lymph nodes, and their function declines with aging. A $\beta$ protein is deposited in and around capillaries, and its accumulation in the brain is largely considered the main cause of Alzheimer's disease.

outer layer of pericytes (PEs). Blood vessel patterns vary markedly among different tissues and organs. The diversity and plasticity of vascular networks are considered important for this system to perform its distinct functions in each tissue and organ (Takashima et al., 2019). Evidence has shown that ECs, which show remarkable structural and functional heterogeneity, may be responsible for this diversity (Aird, 2007). Recent studies have demonstrated that molecular profiles define the heterogeneity of ECs in the capillaries found in different tissues (Nolan et al., 2013; Vanlandewijck et al., 2018). These heterogeneous differences were confirmed by both in vitro differentiation and an in vivo transplantation system (Nolan et al., 2013).

Oxygen level is a particularly important element in the regulation of ECs and PEs and determines how tissue vascularization is constructed. In hypoxic cells, hypoxiainducible factor- $1 \alpha$ (HIF- $1 \alpha)$ is activated (Semenza and Wang, 1992) and drives vascular endothelial growth factor (VEGF) and other hypoxia-responsive genes. It also regulates the recruitment of endothelial progenitor cells in the endothelial lining of blood vessels to vascularization sites (Kelly et al., 2003). It has been suggested that these dynamic changes in expression during the developmental process play an important role in the construction of the brain's vascular network (Gustafsson et al., 2005; Li et al., 2014; Wagenführ et al., 2015; Lange et al., 2016), but its specific details of this process have not yet been discovered.

CNS cells, including neurons and glial cells (e.g., astrocytes and microglia), closely interact with angiogenesis and vasculogenesis (Ma et al., 2013; Takahashi et al., 2015; Tan et al., 2016; Himmels et al., 2017). In a recent study, we found that an avascular region without a capillary invasion was specifically constructed in the $\mathrm{VZ}$ where mitotic progenitors are located, and NSPCs transiently expressed HIF-1 $\alpha$ and VEGF, thereby attracting vascular endothelial tip cells (KomabayashiSuzuki et al., 2019). The expression level of these proteins in the VZ gradually decreased, while their levels gradually increased in the intermediate zone (IZ) at later developmental stages (Komabayashi-Suzuki et al., 2019). Another recent study demonstrated that HIF-1 $\alpha$ stabilization is required for the maturation arrest of oligodendrocyte progenitor cells (OPCs) through $W n t 7 a / 7 b$ activation (Yuen et al., 2014). Furthermore, we showed that OPCs come into contact with ECs frequently in the IZ and that the spatiotemporal HIF-1 $\alpha$ activation corresponds with the timing of OPC maturation (Komabayashi-Suzuki et al., 2019). This suggests that the spatiotemporal regulation of HIF- $1 \alpha$ and VEGF expression plays an essential role in the cytoarchitecture of both the vascular system and the neural system in the neocortex.

\section{THE BRAIN-SPECIFIC CAPILLARY STRUCTURE BREAKS DOWN WITH AGING}

The structural integrity of the vessels declines with age (Figure 1). Additionally, there is considerable evidence of declines in capillary density throughout the aged brain (Klein and Michel, 1977; Wilkinson et al., 1981; Reeson et al., 2018). Current evidence suggests that neocortical microvascular pathologies, such as age-related structural and functional declines in the vascular plexus (e.g., vascular rarefaction), contributes to age-related cognitive dysfunction and neurodegeneration 
(van Dijk et al., 2008; Brown and Thore, 2011). Moreover, there appears to be an age-related decline in the neovascularization capacity by various mechanisms. For example, HIF- $1 \alpha$ becomes less responsive to hypoxia during aging. VEGF also becomes less responsive during aging, even in the presence of sufficient VEGF levels. This is probably due to an intrinsic change in VEGF-receptor 2 (Gao et al., 2009), and a reduction in the expression level of VEGF itself (Frenkel-Denkberg et al., 1999; Rivard et al., 2000). Hence, the potential for tissues to undergo vascular remodeling is age-related and results in decreased blood flow in the aged neocortex (Katsimpardi et al., 2014). The mesenchyme homeobox gene, MEOX2, encodes a family of homeodomain transcription factors expressed in the vascular system (Gorski and Walsh, 2003). MEOX2 has the potential to regulate the expression of many target genes, and can therefore modify the phenotype, and function of vascular cells. Deletion of Meox2 leads to the reduction of brain capillary density, which causes resting CBF to diminish, and the angiogenic response to hypoxia in the brain to be lost (Wu et al., 2005). In adult vasculature, Meox2 is predominantly expressed in ECs and modulates angiogenesis and vascular network construction. Meox2 that has gained or lost its function can also cause the vascular structure to be altered ( $\mathrm{Wu}$ et al., 2005; Gohn et al., 2017). Also, Meox2 expression in vascular smooth muscle cells (VSMCs) is downregulated in response to serum, growth factors, and vascular injury (Gorski et al., 1993; Weir et al., 1995). These studies support a role for Meox2 in the maintenance of vascular integrity.

It is well known that age-related endothelial dysfunction is associated with prominent changes in the $\mathrm{BBB}$, and aberrant activities within the neurovascular unit (NVU; Cai et al., 2017; Li et al., 2019). The BBB is a complex functional and anatomical structure composed of brain microvascular ECs that communicate with PEs and astrocytes, which enables these cells to organize into a well-structured NVU with neurons (Banks et al., 2018; Figure 1). Cerebral capillary ECs contain tight junctions, which tightly sealed cell-to-cell contact between adjacent ECs to form a continuous vascular system. This tight seals between cells lead to high endothelial electrical resistance, and low paracellular/transcellular permeability (Zlokovic, 2008). Recent studies have indicated that $\mathrm{Wnt} / \beta$ catenin signaling is a key pathway required for both the formation of $\mathrm{BBB}$ functions, and the maintenance of $\mathrm{BBB}$ integrity (Engelhardt and Liebner, 2014; Liebner et al., 2018). The binding of the Wnt ligands, Wnt7a and Wnt7b, produced by neurons and astrocytes in the brain (Zhang et al., 2014) to the corresponding Wnt receptor, Fzd4, and Wnt coreceptor, LRP5/6, triggers the activation of $\mathrm{Wnt} / \beta$-catenin signaling in $\mathrm{BBB}$ formation and function (Liebner et al., 2008; Stenman et al., 2008; Daneman et al., 2009). Also, GPI-anchored Reck and G protein-coupled receptor, Gpr124, have been implicated in Wnt7a/Wnt7b-specific signaling in mammalian CNS angiogenesis, BBB integrity, and function (Zhou and Nathans, 2014; Vanhollebeke et al., 2015; Tran et al., 2016; Chang et al., 2017; Cho et al., 2017; Vallon et al., 2018; Laksitorini et al., 2019).

\section{VASCULAR DYSFUNCTION IS AN INTEGRAL PART OF ALZHEIMER'S DISEASE PATHOGENESIS}

$\mathrm{AD}$ is the most common neurodegenerative disease, accounting for an estimated 60 to $80 \%$ of dementia cases. Emerging evidence indicates an important vascular contribution to $A D$, since $A \beta$ protein is deposited in and around capillaries, and aberrant $\mathrm{A} \beta$ protein accumulation in the tissue is largely considered to be the main cause of $\mathrm{AD}$ (Liesz, 2019). Recent reports suggest that the common sporadic form of $\mathrm{AD}$ (late-onset), and some familial cases of AD (early onset) are characterized by elevated $A \beta$ brain levels as a result of impaired $A \beta$ elimination instead of overproduction (Mawuenyega et al., 2010). Normally, low $A \beta$ levels in the brain are maintained through degradation, and elimination via its transvascular removal across the $\mathrm{BBB}$, which results in the removal of $85 \%$ of $A \beta$. Removal of the remaining $15 \%$ normally occurs via the interstitial fluid (ISF) bulk flow along the outside of penetrating arteries, and subsequent cerebrospinal fluid (CSF) absorption in the circulatory and lymphatic system (Deane et al., 2004, 2008; Nelson et al., 2017; Figure 2).

Brain ECs with tight junctions form the $\mathrm{BBB}$. It is generally believed that neurodegeneration is accompanied by $\mathrm{BBB}$ dysfunction (Figure 1), which begins as early as middle age in rodents and humans. Vascular damage is the initial insult, causing disrupted $\mathrm{BBB}$ function and impaired brain perfusion that contributes to neuronal injury, and dementia (Montagne et al., 2020; Musaeus et al., 2020). BBB disruption occurs as capillary leakage, the deregulation of ECs-PEsglial communications, brain leukocyte infiltration, or aberrant angiogenesis (Armulik et al., 2011; Sweeney et al., 2018b). The cell-surface receptor, low-density lipoprotein receptorrelated protein-1 (LRP1), has been reported to mediate $A \beta$ endocytosis across the BBB (Kanekiyo et al., 2012, 2013), and $\mathrm{A} \beta$ transcytosis through the brain endothelium, as well as its subsequent systemic elimination via the liver, spleen, and kidney (Shibata et al., 2000). LRP1 expression in the brain and brain capillaries has been shown to decrease with age (Shibata et al., 2000; Deane et al., 2008; Silverberg et al., 2010; Storck et al., 2016), and its expression is further reduced in AD (Kang et al., 2000; Shibata et al., 2000). A $\beta$ influx transport, from the plasma into the brain ISF occurs via the receptor for advanced glycation end products (RAGE), which promotes inflammation (Deane et al., 2003). Vascular aging in the brain of $\mathrm{AD}$ patients, which includes reduced capillary length, and decreased tight junction protein expression, might reflect aberrant angiogenesis potential that originated from the impairment of Meox2 expression in ECs (Zlokovic, 2011). In addition, $\mathrm{BBB}$ disruption upregulates transforming growth factor- $\alpha$ (TGF- $\alpha$ ) signaling in astrocytes, resulting in neural dysfunction (Senatorov et al., 2019).

Interactions between ECs and mural cells, which include PEs and VSMCs, have recently come into focus as regulators of vascular formation, stabilization, remodeling, and function. 
Platelet-derived growth factor receptor- $\beta$ (PDGFR $\beta$ ) is predominantly expressed in the mural cells, such as capillary PEs and VSMCs. Expression levels of PDGFR $\beta$ in PEs are noticeably higher than those in VSMCs. Additionally, PEs control $A \beta$ clearance from the brain. Their loss diminishes the removal of soluble $A \beta$ and accelerates the onset and progression of disease pathogenesis in mouse models of $\mathrm{AD}$ (Sagare et al., 2013). PE-derived trophic supports that maintain a healthy brain might also be lacking in $\mathrm{AD}$, and $\mathrm{PE}$ loss may contribute to a progressive, age-dependent, vascularmediated neurodegeneration in animal models (Bell et al., 2010; Armulik et al., 2011; Nikolakopoulou et al., 2019). The numbers of PDGFR $\beta$-positive PEs, PE coverage of the capillary, and the number of capillaries are all reduced in the $\mathrm{AD}$ patient brain, which shows evidence of a gene-dose effect associated with the number of APOE4 alleles (Sengillo et al., 2013). Brain capillary damage using a novel CSF biomarker of BBB-associated capillary PEs, PDGFR $\beta$, and regional BBB permeability were developed in the hippocampus of individuals with early cognitive decline independent of $A \beta$ and tau pathology, suggesting that $\mathrm{BBB}$ damage is an early biomarker of human cognitive dysfunction, including the early stages of AD (Nation et al., 2019). Furthermore, elevated PDGFR $\beta$ in the CSF was shown to predict cognitive decline in APOE4 carriers (Montagne et al., 2020).

The lymphatic drainage system was thought for many years to be absent in the mammalian brain. It is now accepted that meningeal lymphatic vessels remove macromolecules, such as $\mathrm{A} \beta$ protein, from the parenchyma into the cervical lymph nodes (Figure 2), due to the rediscovery and characterization of the CNS lymphatic system (Aspelund et al., 2015; Louveau et al., 2015). Furthermore, a recent study has shown that older mice have impaired brain perfusion of macromolecules compared with that of young mice, accompanied by a decrease in meningeal lymphatic vessel diameter and coverage (Da Mesquita et al., 2018). Another recent study demonstrated that basal meningeal lymphatic vessels are hotspots for the clearance of CSF macromolecules and that its function of drainage from the brain to the periphery is impaired with aging (Ahn et al., 2019). Moreover, the treatment of aged mice with VEGF-C enhanced drainage, which leads to learning and memory improvements (Da Mesquita et al., 2018). A study of the effects of the disruption of meningeal lymphatic vessels in $\mathrm{AD}$ mouse models confirmed that ablation led to the promotion of $\mathrm{A} \beta$ accumulation in the meninges (Da Mesquita et al., 2018), which is similar to human pathology.

\section{CELL THERAPY TARGETING OF NEOVASCULARIZATION FOR NEURAL DISEASE TREATMENTS}

Collectively, these studies suggest that the structural and functional integrity of the vascular system is essential for normal brain function. Improvement of the vascular system may be a promising therapeutic strategy for improving neural disease treatment. There is now an enormous demand for new effective therapies in neural diseases, such as $\mathrm{AD}$, because of a high and unmet medical need to treat these neural diseases. With this perspective, advances in stem cell-based therapies that aim to repopulate or regenerate a degenerating vascular system have been anticipated (Figure 1).

Mesenchymal stem cells (MSCs) have attracted attention due to their powerful intrinsic cell therapy properties, although the molecular mechanisms of their physiological action have not yet been clarified. Transplantation of MSCs derived from the human umbilical cord (Lee H. et al., 2012; Yang et al., 2013), placenta (Yun et al., 2013), and bone marrow (Naaldijk et al., 2017) has been reported to inhibit $A \beta$-induced cell death, reduce $A \beta$ plaque size (Yang et al., 2013; Yun et al., 2013; Naaldijk et al., 2017), and rescue spatial learning and memory disorders (Lee H. et al., 2012; Yang et al., 2013; Yun et al., 2013) in rodent AD models. Another study demonstrated that intravenous administration of ischemia-tolerant MSCs displayed significant $A \beta$ degradation, and had an anti-inflammatory impact in an AD mouse model (Harach et al., 2017). Intriguingly, both bone marrow-derived MSCs and adipose-derived stem cells (ASCs) have been shown to enhance vascular tube formation in a co-culture system (Ghajar et al., 2010; Verseijden et al., 2010; Duttenhoefer et al., 2013). Additionally, ASCs express angiogenic factors such as VEGF under hypoxic conditions (Rohringer et al., 2014). Moreover, MSCs have the potential to induce the differentiation of mural cells, such as PEs, by gap junctiondependent communication between MSCs and ECs (Hirschi et al., 2003). Also, bone marrow mononuclear cells (BM-MNC) have been shown to activate the repopulation or regeneration of neovascularization in ischemic tissue (Tateishi-Yuyama et al., 2002; Taguchi et al., 2003). Furthermore, a recent study has demonstrated that transplanted BM-MNCs activate angiogenesis through gap junction-mediated, direct cell-to-cell interactions between BM-MNC and ECs, followed by activation of HIF$1 \alpha$, and suppression of autophagy in the ECs of ischemic brain tissue (Kikuchi-Taura et al., 2020). These studies suggest that stem cell-based therapies, which have utilized MSCs, ASCs, and BM-MNCs, have great potential for neovascularization in neural diseases.

In other words, it is possible to lead to the creation of new concepts on the development/progression of neural diseases, in which vascular aging is involved, by the effect of improving pathological conditions by the protective actions on neovascularization, including the response mechanisms, in which the brain capillaries undergo the actions by the physical contact between MSCs/ASCs/BM-MNCs and ECs, and by MSCs/ASCs/BM-MNCs-derived humoral factors.

\section{CONCLUSIONS AND PERSPECTIVES}

Interactions between vascular cells and neural cells play an essential role in both brain development and brain aging. In this review article, we summarized how ECs construct a vascular plexus, and that capillary networks with tissue-specific environments may control neocortical development, allowing each region to maintain various distinct functions. Capillaries in the neocortex are prone to obstruction with aging, and this 
event has a major impact on brain function. The dysfunction of the vascular system is an integral part of $\mathrm{AD}$ etiology and pathophysiology. $A \beta$ has been thought to be mainly generated in the brain itself, but accumulating evidence suggests that $A \beta$ is generated in both the brain and peripheral tissues ( $\mathrm{Bu}$ et al., 2018). This underscores the relevance of the dysfunction of the vascular system, including lymphatic vessels, in $\mathrm{AD}$.

In the future, to deeply understand brain aging/pathological conditions, it is necessary to elucidate further the progression mechanism of vascular aging by clarifying which linkage breakdown between the vascular system and neural system causes preferential degradation of any capillaries in any tissue. Also, by applying these basic findings, it is expected to lead to the establishment of new therapeutic concepts, such as stem

\section{REFERENCES}

Ahn, J. H., Cho, H., Kim, J. H., Kim, S. H., Ham, J. S., Park, I., et al. (2019). Meningeal lymphatic vessels at the skull base drain cerebrospinal fluid. Nature 572, 62-66. doi: 10.1038/s41586-019-1419-5

Aird, W. C. (2007). Phenotypic heterogeneity of the endothelium: I. Structure, function, and mechanisms. Circ. Res. 100, 158-173. doi: 10.1161/01.RES. $0000255691.76142 .4 \mathrm{a}$

Armulik, A., Genové, G., and Betsholtz, C. (2011). Pericytes: developmental, physiological, and pathological perspectives, problems and promises. Dev. Cell 21, 193-215. doi: 10.1016/j.devcel.2011.07.001

Aspelund, A., Antila, S., Proulx, S. T., Karlsen, T. V., Karaman, S., Detmar, M., et al. (2015). A dural lymphatic vascular system that drains brain interstitial fluid and macromolecules. J. Exp. Med. 212, 991-999. doi: 10.1084/jem.20142290

Attems, J., and Jellinger, K. A. (2014). The overlap between vascular disease and Alzheimer's disease-lessons from pathology. BMC Med. 12:206. doi: 10.1186/s12916-014-0206-2

Banks, W. A., Kovac, A., and Morofuji, Y. (2018). Neurovascular unit crosstalk: pericytes and astrocytes modify cytokine secretion patterns of brain endothelial cells. J. Cereb. Blood Flow Metab. 38, 1104-1118. doi: 10.1177/ $0271678 X 17740793$

Bayer, S. A., and Altman, J. (1991). Neocortical Development. New York, NY: Raven Press.

Bell, R. D., Winkler, E. A., Sagare, A. P., Singh, I., LaRue, B., Deane, R., et al. (2010). Pericytes control key neurovascular functions and neuronal phenotype in the adult brain and during brain aging. Neuron 68, 409-427. doi: 10.1016/j.neuron.2010.09.043

Bennett, R. E., Robbins, A. B., Hu, M., Cao, X., Betensky, R. A., Clark, T., et al. (2018). Tau induces blood vessel abnormalities and angiogenesis-related gene expression in P301L transgenic mice and human Alzheimer's disease. Proc. Natl. Acad. Sci. U S A 115, E1289-E1298. doi: 10.1073/pnas.1710329115

Bjornsson, C. S., Apostolopoulou, M., Tian, Y., and Temple, S. (2015). It takes a village: constructing the neurogenic niche. Dev. Cell 32, 435-446. doi: 10.1016/j. devcel.2015.01.010

Brown, W. R., and Thore, C. R. (2011). Review: cerebral microvascular pathology in ageing and neurodegeneration. Neuropathol. Appl. Neurobiol. 37, 56-74. doi: 10.1111/j.1365-2990.2010.01139.x

Bu, X.-L., Xiang, Y., Jin, W.-S., Wang, J., Shen, L.-L., Huang, Z.-L., et al. (2018). Blood-derived amyloid- $\beta$ protein induces Alzheimer's disease pathologies. Mol. Psychiatry 23, 1948-1956. doi: 10.1038/mp.2017.204

Cai, W., Zhang, K., Li, P., Zhu, L., Xu, J., Yang, B., et al. (2017). Dysfunction of the neurovascular unit in ischemic stroke and neurodegenerative diseases: an aging effect. Ageing Res. Rev. 34, 77-87. doi: 10.1016/j.arr.2016.09.006

Castellano, J. M., Mosher, K. I., Abbey, R. J., McBride, A. A., James, M. L., Berdnik, D., et al. (2017). Human umbilical cord plasma proteins revitalize hippocampal function in aged mice. Nature 544, 488-492. doi: $10.1038 /$ nature 22067 cell therapy, and the development of the prevention of neural diseases/new therapeutics through the mechanism of inhibiting vascular aging.

\section{AUTHOR CONTRIBUTIONS}

All authors drafted the manuscript, discussed, and approved the final manuscript.

\section{ACKNOWLEDGMENTS}

This work was supported by JSPS KAKENHI Grant Number 19K07259.

Chang, J., Mancuso, M. R., Maier, C., Liang, X., Yuki, K., Yang, L., et al. (2017) Gpr124 is essential for blood-brain barrier integrity in central nervous system disease. Nat. Med. 23, 450-460. doi: 10.1038/nm.4309

Chen, M. B., Yang, A. C., Yousef, H., Lee, D., Chen, W., Schaum, N., et al. (2020). Brain endothelial cells are exquisite sensors of age-related circulatory cues. Cell Rep. 30, 4418-4432. doi: 10.1016/j.celrep.2020.03.012

Cho, C., Smallwood, P. M., and Nathans, J. (2017). Reck and Gpr124 are essential receptor cofactors for Wnt7a/Wnt7b-specific signaling in mammalian CNS angiogenesis and blood-brain barrier regulation. Neuron 95, 1056.e5-1073.e5. doi: 10.1016/j.neuron.2017.07.031

Da Mesquita, S., Louveau, A., Vaccari, A., Smirnov, I., Cornelison, R. C., Kingsmore, K. M., et al. (2018). Functional aspects of meningeal lymphatics in ageing and Alzheimer's disease. Nature 560, 185-191. doi: 10.1038/s41586018-0368-8

Daneman, R., Agalliu, D., Zhou, L., Kuhnert, F., Kuo, C. J., and Barres, B. A. (2009). $\mathrm{Wnt} / \beta$-catenin signaling is required for $\mathrm{CNS}$, but not non-CNS, angiogenesis. Proc. Natl. Acad. Sci. U S A 106, 641-646. doi: 10.1073/pnas.0805165106

Deane, R., Du Yan, S., Submamaryan, R. K., LaRue, B., Jovanovic, S., Hogg, E., et al. (2003). RAGE mediates amyloid- $\beta$ peptide transport across the blood-brain barrier and accumulation in brain. Nat. Med. 9, 907-913. doi: 10.1038/nm890

Deane, R., Sagare, A., Hamm, K., Parisi, M., Lane, S., Finn, M. B., et al. (2008). ApoE isoform-specific disruption of amyloid $\beta$ peptide clearance from mouse brain. J. Clin. Invest. 118, 4002-4013. doi: 10.1172/jci36663

Deane, R., Wu, Z., Sagare, A., Davis, J., Du Yan, S., Hamm, K., et al. (2004). LRP/amyloid $\beta$-peptide interaction mediates differential brain efflux of $A \beta$ isoforms. Neuron 43, 333-344. doi: 10.1016/j.neuron.2004.07.017

Duttenhoefer, F., Lara de Freitas, R., Meury, T., Loibl, M., Benneker, L. M., Richards, R. G., et al. (2013). 3D scaffolds co-seeded with human endothelial progenitor and mesenchymal stem cells: evidence of prevascularisation within 7 days. Eur. Cell Mater. 26, 49-64; discussion 64-65. doi: 10.22203/ecm.v026a04

Engelhardt, B., and Liebner, S. (2014). Novel insights into the development and maintenance of the blood-brain barrier. Cell Tissue Res. 355, 687-699. doi: 10.1007/s00441-014-1811-2

Franco, S. J., and Müller, U. (2013). Shaping our minds: stem and progenitor cell diversity in the mammalian neocortex. Neuron 77, 19-34. doi: 10.1016/j. neuron.2012.12.022

Frenkel-Denkberg, G., Gershon, D., and Levy, A. P. (1999). The function of hypoxia-inducible factor 1 (HIF-1) is impaired in senescent mice. FEBS Lett. 462, 341-344. doi: 10.1016/s0014-5793(99)01552-5

Gao, T., Lin, Z., and Jin, X. (2009). Hydrocortisone suppression of the expression of VEGF may relate to toll-like receptor (TLR) 2 and 4. Curr. Eye Res. 34, 777-784. doi: 10.1080/02713680903067919

Ghajar, C. M., Kachgal, S., Kniazeva, E., Mori, H., Costes, S. V., George, S. C., et al. (2010). Mesenchymal cells stimulate capillary morphogenesis via distinct proteolytic mechanisms. Exp. Cell Res. 316, 813-825. doi: 10.1016/j.yexcr.2010.01.013 
Gohn, C. R., Blue, E. K., Sheehan, B. M., Varberg, K. M., and Haneline, L. S. (2017). Mesenchyme homeobox 2 enhances migration of endothelial colony forming cells exposed to intrauterine diabetes mellitus. J. Cell Physiol. 232, 1885-1892. doi: $10.1002 /$ jcp. 25734

Gorski, D. H., LePage, D. F., Patel, C. V., Copeland, N. G., Jenkins, N. A., and Walsh, K. (1993). Molecular cloning of a diverged homeobox gene that is rapidly down-regulated during the G0/G1 transition in vascular smooth muscle cells. Mol. Cell Biol. 13, 3722-3733. doi: 10.1128/mcb.13.6.3722

Gorski, D. H., and Walsh, K. (2003). Control of vascular cell differentiation by homeobox transcription factors. Trends Cardiovasc. Med. 13, 213-220. doi: 10.1016/s1050-1738(03)00081-1

Gustafsson, M. V., Zheng, X., Pereira, T., Gradin, K., Jin, S., Lundkvist, J., et al. (2005). Hypoxia requires notch signaling to maintain the undifferentiated cell state. Dev. Cell 9, 617-628. doi: 10.1016/j.devcel.2005.09.010

Harach, T., Jammes, F., Muller, C., Duthilleul, N., Cheatham, V., Zufferey, V., et al. (2017). Administrations of human adult ischemia-tolerant mesenchymal stem cells and factors reduce amyloid $\beta$ pathology in a mouse model of Alzheimer's disease. Neurobiol. Aging 51, 83-96. doi: 10.1016/j.neurobiolaging.2016.11.009

Himmels, P., Paredes, I., Adler, H., Karakatsani, A., Luck, R., Marti, H. H., et al. (2017). Motor neurons control blood vessel patterning in the developing spinal cord. Nat. Commun. 8:14583. doi: 10.1038/ncomms14583

Hirschi, K. K., Burt, J. M., Hirschi, K. D., and Dai, C. (2003). Gap junction communication mediates transforming growth factor- $\beta$ activation and endothelial-induced mural cell differentiation. Circ. Res. 93, 429-437. doi: 10.1161/01.res.0000091259.84556.d5

Inoue, M., Iwai, R., Tabata, H., Konno, D., Suzuki-Komabayashi, M., Watanabe, C., et al. (2017). Prdm16 is crucial for progression of the multipolar phase during neural differentiation of the developing neocortex. Development 144, 385-399. doi: 10.1242/dev.136382

Kanekiyo, T., Liu, C. C., Shinohara, M., Li, J., and Bu, G. (2012). LRP1 in brain vascular smooth muscle cells mediates local clearance of Alzheimer's amyloid-B. J. Neurosci. 32, 16458-16465. doi: 10.1523/JNEUROSCI.398712.2012

Kanekiyo, T., Cirrito, J. R., Liu, C. C., Shinohara, M., Li, J., Schuler, D. R., et al. (2013). Neuronal clearance of amyloid- $\beta$ by endocytic receptor LRP1. J. Neurosci. 33, 19276-19283. doi: 10.1523/JNEUROSCI.3487-13.2013

Kang, D. E., Pietrzik, C. U., Baum, L., Chevallier, N., Merriam, D. E., Kounnas, M. Z., et al. (2000). Modulation of amyloid $\beta$-protein clearance and Alzheimer's disease susceptibility by the LDL receptor-related protein pathway. J. Clin. Invest. 106, 1159-1166. doi: 10.1172/JCI11013

Katsimpardi, L., Litterman, N. K., Schein, P. A., Miller, C. M., Loffredo, F. S., Wojtkiewicz, G. R., et al. (2014). Vascular and neurogenic rejuvenation of the aging mouse brain by young systemic factors. Science 344, 630-634. doi: $10.1126 /$ science.1251141

Kelly, B. D., Hackett, S. F., Hirota, K., Oshima, Y., Cai, Z., Berg-Dixon, S., et al. (2003). Cell type-specific regulation of angiogenic growth factor gene expression and induction of angiogenesis in nonischemic tissue by a constitutively active form of hypoxia-inducible factor 1. Circ. Res. 93, 1074-1081. doi: 10.1161/01.res.0000102937.50486.1b

Kikuchi-Taura, A., Okinaka, Y., Takeuchi, Y., Ogawa, Y., Maeda, M., Kataoka, Y., et al. (2020). Bone marrow mononuclear cells activate angiogenesis via gap junction-mediated cell-cell interaction. Stroke 51, 1279-1289. doi: 10.1161/strokeaha.119.028072

Klein, A. W., and Michel, M. E. (1977). A morphometric study of the neocortex of young adult and old maze-differentiated rats. Mech. Ageing Dev. 6, 441-452. doi: 10.1016/0047-6374(77)90045-8

Kokovay, E., Goderie, S., Wang, Y., Lotz, S., Lin, G., Sun, Y., et al. (2010). Adult SVZ lineage cells home to and leave the vascular niche via differential responses to SDF1/CXCR4 signaling. Cell Stem Cell 7, 163-173. doi: 10.1016/j.stem.2010.05.019

Komabayashi-Suzuki, M., Yamanishi, E., Watanabe, C., Okamura, M., Tabata, H., Iwai, R., et al. (2019). Spatiotemporally dependent vascularization is differently utilized among neural progenitor subtypes during neocortical development. Cell Rep. 29, 1113-1129. doi: 10.1016/j.celrep.2019.09.048

Laksitorini, M. D., Yathindranath, V., Xiong, W., Hombach-Klonisch, S., and Miller, D. W. (2019). Modulation of Wnt/ $\beta$-catenin signaling promotes bloodbrain barrier phenotype in cultured brain endothelial cells. Sci. Rep. 9:19718. doi: 10.1002/jnr.24687/v1/review3
Lange, C., Turrero Garcia, M., Decimo, I., Bifari, F., Eelen, G., Quaegebeur, A., et al. (2016). Relief of hypoxia by angiogenesis promotes neural stem cell differentiation by targeting glycolysis. EMBO J. 35, 924-941. doi: $10.15252 / \mathrm{embj} .201592372$

Lee, P., Kim, J., Williams, R., Sandhir, R., Gregory, E., Brooks, W. M., et al. (2012). Effects of aging on blood brain barrier and matrix metalloproteases following controlled cortical impact in mice. Exp. Neurol. 234, 50-61. doi: 10.1016/j. expneurol.2011.12.016

Lee, H. J., Lee, J. K., Lee, H., Carter, J. E., Chang, J. W., Oh, W., et al. (2012). Human umbilical cord blood-derived mesenchymal stem cells improve neuropathology and cognitive impairment in an Alzheimer's disease mouse model through modulation of neuroinflammation. Neurobiol. Aging 33, 588-602. doi: 10.1016/j.neurobiolaging.2010.03.024

Li, L., Candelario, K. M., Thomas, K., Wang, R., Wright, K., Messier, A., et al. (2014). Hypoxia inducible factor- $1 \alpha(\mathrm{HIF}-1 \alpha)$ is required for neural stem cell maintenance and vascular stability in the adult mouse SVZ. J. Neurosci. 34, 16713-16719. doi: 10.1523/JNEUROSCI.4590-13.2014

Li, Y., Xie, L., Huang, T., Zhang, Y., Zhou, J., Qi, B., et al. (2019). Tissue specific origin, aging neurovascular unit and potential role of DNA damage and repair in combating vascular and neurodegenerative disorders. Front. Neurosci. 13:778. doi: 10.3389/fnins.2019.00778

Liebner, S., Corada, M., Bangsow, T., Babbage, J., Taddei, A., Czupalla, C. J., et al. (2008). Wnt/ $\beta$-catenin signaling controls development of the blood-brain barrier. J. Cell Biol. 83, 409-417. doi: 10.1083/jcb.200806024

Liebner, S., Dijkhuizen, R. M., Reiss, Y., Plate, K. H., Agalliu, D., and Constantin, G. (2018). Functional morphology of the blood-brain barrier in health and disease. Acta Neuropathol. 135, 311-336. doi: 10.1007/s00401-0181815-1

Liesz, A. (2019). The vascular side of Alzheimer's disease. Science 365, 223-224. doi: $10.1126 /$ science.aay 2720

Louveau, A., Smirnov, I., Keyes, T. J., Eccles, J. D., Rouhani, S. J., Peske, J. D., et al. (2015). Structural and functional features of central nervous system lymphatic vessels. Nature 523, 337-341. doi: 10.3389/fnins.2015.00485

Ma, S., Kwon, H. J., Johng, H., Zang, K., and Huang, Z. (2013). Radial glial neural progenitors regulate nascent brain vascular network stabilization via inhibition of Wnt signaling. PLoS Biol. 11:e1001469. doi: 10.1371/journal.pbio. 1001469

Mawuenyega, K. G., Sigurdson, W., Ovod, V., Munsell, L., Kasten, T., Morris, J. C., et al. (2010). Decreased clearance of CNS $\beta$-amyloid in Alzheimer's disease. Science 330:1774. doi: 10.1126/science.1197623

Montagne, A., Nation, D. A., Sagare, A. P., Barisano, G., Sweeney, M. D., Chakhoyan, A., et al. (2020). APOE4 leads to blood-brain barrier dysfunction predicting cognitive decline. Nature 581, 71-76. doi: 10.1038/s41586-0202247-3

Mizutani, K., Yoon, K., Dang, L., Tokunaga, A., and Gaiano, N. (2007). Differential Notch signaling distinguishes neural stem cells from intermediate progenitors. Nature 449, 351-355. doi: 10.1038/nature06090

Musaeus, C. S., Gleerup, H. S., Høgh, P., Waldemar, G., Hasselbalch, S. G., and Simonsen, A. H. (2020). Cerebrospinal fluid/plasma albumin ratio as a biomarker for blood-brain barrier impairment across neurodegenerative dementias. J. Alzheimers Dis. 75, 429-436. doi: 10.3233/jad-200168

Naaldijk, Y., Jäger, C., Fabian, C., Leovsky, C., Blüher, A., Rudolph, L., et al. (2017). Effect of systemic transplantation of bone marrow-derived mesenchymal stem cells on neuropathology markers in APP/PS1 Alzheimer mice. Neuropathol. Appl. Neurobiol. 43, 299-314. doi: 10.1111/nan.12319

Nation, D. A., Sweeney, M. D., Montagne, A., Sagare, A. P., D’Orazio, L. M., Pachicano, M., et al. (2019). Blood-brain barrier breakdown is an early biomarker of human cognitive dysfunction. Nat. Med. 25, 270-276. doi: 10.1038/s41591-018-0297-y

Nelson, A. R., Sagare, A. P., and Zlokovic, B. V. (2017). Role of clusterin in the brain vascular clearance of amyloid- $\beta$. Proc. Natl. Acad. Sci. U S A 114 , 8681-8682. doi: 10.1073/pnas.1711357114

Nikolakopoulou, A. M., Montagne, A., Kisler, K., Dai, Z., Wang, Y., Huuskonen, M. T., et al. (2019). Pericyte loss leads to circulatory failure and pleiotrophin depletion causing neuron loss. Nat. Neurosci. 22, 1089-1098. doi: 10.1038/s41593-019-0434-z

Nolan, D. J., Ginsberg, M., Israely, E., Palikuqi, B., Poulos, M. G., James, D., et al. (2013). Molecular signatures of tissue-specific microvascular endothelial cell 
heterogeneity in organ maintenance and regeneration. Dev. Cell 26, 204-219. doi: 10.1016/j.devcel.2013.06.017

Osler, W. (1898). The Principles and Practice of Medicine: Designed for the Use of Practitioners and Students of Medicine. New York, NY: Appleton.

Ottone, C., Krusche, B., Whitby, A., Clements, M., Quadrato, G., Pitulescu, M. E., et al. (2014). Direct cell-cell contact with the vascular niche maintains quiescent neural stem cells. Nat. Cell Biol. 16, 1045-1056. doi: 10.1038/ ncb3045

Reeson, P., Choi, K., and Brown, C. E. (2018). VEGF signaling regulates the fate of obstructed capillaries in mouse cortex. eLife 7:e33670. doi: 10.7554/eLife.33670

Rivard, A., Fabre, J. E., Silver, M., Chen, D., Murohara, T., Kearney, M., et al. (1999). Age-dependent impairment of angiogenesis. Circulation 99, 111-120. doi: 10.1161/01.cir.99.1.111

Rivard, A., Berthou-Soulie, L., Principe, N., Kearney, M., Curry, C., Branellec, D., et al. (2000). Age-dependent defect in vascular endothelial growth factor expression is associated with reduced hypoxia-inducible factor 1 activity. J. Biol. Chem. 275, 29643-29647. doi: 10.1074/jbc.m001029200

Rohringer, S., Hofbauer, P., Schneider, K. H., Husa, A. M., Feichtinger, G., Peterbauer-Scherb, A., et al. (2014). Mechanisms of vasculogenesis in 3D fibrin matrices mediated by the interaction of adipose-derived stem cells and endothelial cells. Angiogenesis 17, 921-933. doi: 10.1007/s10456-0149439-0

Sagare, A. P., Bell, R. D., Zhao, Z., Ma, Q., Winkler, E. A., Ramanathan, A., et al. (2013). Pericyte loss influences Alzheimer-like neurodegeneration in mice. Nat. Commun. 4:2932. doi: 10.1038/ncomms3932

Semenza, G. L., and Wang, G. L. (1992). A nuclear factor induced by hypoxia via de novo protein synthesis binds to the human erythropoietin gene enhancer at a site required for transcriptional activation. Mol. Cell Biol. 112, 5447-5454. doi: $10.1128 / \mathrm{mcb} .12 .12 .5447$

Senatorov, V. V. Jr., Friedman, A. R., Milikovsky, D. Z., Ofer, J., SaarAshkenazy, R., Charbash, A., et al. (2019). Blood-brain barrier dysfunction in aging induces hyperactivation of TGF $\beta$ signaling and chronic yet reversible neural dysfunction. Sci. Transl. Med. 11:eaaw8283. doi: 10.1126/scitranslmed. aaw8283

Sengillo, J. D., Winkler, E. A., Walker, C. T., Sullivan, J. S., Johnson, M., and Zlokovic, B. V. (2013). Deficiency in mural vascular cells coincides with bloodbrain barrier disruption in Alzheimer's disease. Brain Pathol. 23, 303-310. doi: 10.1111/bpa.12004

Shen, Q., Goderie, S. K., Jin, L., Karanth, N., Sun, Y., Abramova, N., et al. (2004). Endothelial cells stimulate self-renewal and expand neurogenesis of neural stem cells. Science 304, 1338-1340. doi: 10.1126/science. 1095505

Shen, Q., Wang, Y., Kokovay, E., Lin, G., Chuang, S. M., Goderie, S. K., et al. (2008). Adult SVZ stem cells lie in a vascular niche: a quantitative analysis of niche cell-cell interactions. Cell Stem Cell 3, 289-300. doi: 10.1016/j.stem.2008.07.026

Shibata, M., Yamada, S., Kumar, S. R., Calero, M., Bading, J., Frangione, B., et al. (2000). Clearance of Alzheimer's amyloid-ss(1-40) peptide from brain by LDL receptor-related protein-1 at the blood-brain barrier. J. Clin. Invest. 106, 1489-1499. doi: 10.1172/JCI10498

Silverberg, G. D., Messier, A. A., Miller, M. C., Machan, J. T., Majmudar, S. S., Stopa, E. G., et al. (2010). Amyloid efflux transporter expression at the blood-brain barrier declines in normal aging. J. Neuropathol. Exp. Neurol. 69, 1034-1043. doi: 10.1097/nen.0b013e3181f46e25

Stenman, J. M., Rajagopal, J., Carroll, T. J., Ishibashi, M., McMahon, J., and McMahon, A. P. (2008). Canonical Wnt signaling regulates organ-specific assembly and differentiation of CNS vasculature. Science 322, 1247-1250. doi: 10.1126/science.1164594

Storck, S. E., Meister, S., Nahrath, J., Meißner, J. N., Schubert, N., Di Spiezio, A., et al. (2016). Endothelial LRP1 transports amyloid- $\beta(1-42)$ across the bloodbrain barrier. J. Clin. Invest. 126, 123-136. doi: 10.1172/jci81108

Sun, B. L., Wang, L. H., Yang, T., Sun, J. Y., Mao, L. L., Yang, M. F., et al. (2018). Lymphatic drainage system of the brain: a novel target for intervention of neurological diseases. Prog. Neurobiol. 163-164, 118-143. doi: 10.1016/j. pneurobio.2017.08.007

Sweeney, M. D., Kisler, K., Montagne, A., Toga, A. W., and Zlokovic, B. V. (2018a). The role of brain vasculature in neurodegenerative disorders. Nat. Neurosci. 21, 1318-1331. doi: 10.1038/s41593-018-0234-x
Sweeney, M. D., Sagare, A. P., and Zlokovic, B. V. (2018b). Blood-brain barrier breakdown in Alzheimer disease and other neurodegenerative disorders. Nat. Rev. Neurol. 14, 133-150. doi: 10.1038/nrneurol.2017.188

Taguchi, A., Ohtani, M., Soma, T., Watanabe, M., and Kinosita, N. (2003). Therapeutic angiogenesis by autologous bone-marrow transplantation in a general hospital setting. Eur. J. Vasc. Endovasc. Surg. 25, 276-278. doi: 10.1053/ ejvs.2002.1831

Tateishi-Yuyama, E., Matsubara, H., Murohara, T., Ikeda, U., Shintani, S., Masaki, H., et al. (2002). Therapeutic angiogenesis for patients with limb ischaemia by autologous transplantation of bone-marrow cells: a pilot study and a randomised controlled trial. Lancet 360, 427-435. doi: 10.1016/s01406736(02)09670-8

Takahashi, T., Takase, Y., Yoshino, T., Saito, D., Tadokoro, R., and Takahashi, Y. (2015). Angiogenesis in the developing spinal cord: blood vessel exclusion from neural progenitor region is mediated by VEGF and its antagonists. PLoS One 10:e0116119. doi: 10.1371/journal.pone.0116119

Takashima, S., Watanabe, C., Ema, M., and Mizutani, K. (2019). Interaction of the nervous system and vascular system is required for the proper assembly of the neocortex. Neurochem. Int. 129:104481. doi: 10.1016/j.neuint. 2019.104481

Tan, X., Liu, W. A., Zhang, X. J., Shi, W., Ren, S. Q., Li, Z., et al. (2016). Vascular influence on ventral telencephalic progenitors and neocortical interneuron production. Dev. Cell 36, 624-638. doi: 10.1016/j.devcel.2016. 02.023

Tarumi, T., and Zhang, R. (2018). Cerebral blood flow in normal aging adults: cardiovascular determinants, clinical implications, and aerobic fitness. J. Neurochem. 144, 595-608. doi: 10.1111/jnc.14234

Tavazoie, M., Van der Veken, L., Silva-Vargas, V., Louissaint, M., Colonna, L., Zaidi, B., et al. (2008). A specialized vascular niche for adult neural stem cells. Cell Stem Cell 3, 279-288. doi: 10.1016/j.stem.2008.07.025

Tran, K. A., Zhang, X., Predescu, D., Huang, X., Machado, R. F., Göthert, J. R., et al. (2016). Endothelial $\beta$-catenin signaling is required for maintaining adult blood-brain barrier integrity and central nervous system homeostasis. Circulation 133, 177-186. doi: 10.1161/CIRCULATIONAHA 115.015982

Vallon, M., Yuki, K., Nguyen, T. D., Chang, J., Yuan, J., Siepe, D., et al. (2018). A RECK-WNT7 receptor-ligand interaction enables isoform-specific regulation of wnt bioavailability. Cell Rep. 25, 339.e9-349.e9. doi: 10.1016/j.celrep.2018. 09.045

van Dijk, E. J., Prins, N. D., Vrooman, H. A., Hofman, A., Koudstaal, P. J., and Breteler, M. M. (2008). Progression of cerebral small vessel disease in relation to risk factors and cognitive consequences: rotterdam scan study. Stroke 39, 2712-2719. doi: 10.1161/strokeaha.107.513176

Vanhollebeke, B., Stone, O. A., Bostaille, N., Cho, C., Zhou, Y., Maquet, E., et al. (2015). Tip cell-specific requirement for an atypical Gpr124- and Reck-dependent Wnt/ $\beta$-catenin pathway during brain angiogenesis. eLife 4:e06489. doi: 10.7554/eLife.06489

Vanlandewijck, M., He, L., Mäe, M. A., Andrae, J., Ando, K., Del Gaudio, F., et al. (2018). A molecular atlas of cell types and zonation in the brain vasculature. Nature 554, 475-480. doi: 10.1038/nature25739

Vasudevan, A., Long, J. E., Crandall, J. E., Rubenstein, J. L., and Bhide, P. G. (2008). Compartment-specific transcription factors orchestrate angiogenesis gradients in the embryonic brain. Nat. Neurosci. 11, 429-439. doi: 10. $1038 / \mathrm{nn} 2074$

Verseijden, F., Posthumus-van Sluijs, S. J., Pavljasevic, P., Hofer, S. O., van Osch, G. J., and Farrell, E. (2010). Adult human bone marrow- and adipose tissue-derived stromal cells support the formation of prevascular-like structures from endothelial cells in vitro. Tissue Eng. Part 16, 101-114. doi: 10.1089/ten.tea.2009.0106

Villeda, S. A., Luo, J., Mosher, K. I., Zou, B., Britschgi, M., Bieri, G., et al. (2011). The ageing systemic milieu negatively regulates neurogenesis and cognitive function. Nature 477, 90-94. doi: 10.1038/nature10357

Wagenführ, L., Meyer, A. K., Braunschweig, L., Marrone, L., and Storch, A. (2015). Brain oxygen tension controls the expansion of outer subventricular zone-like basal progenitors in the developing mouse brain. Development 142, 2904-2915. doi: $10.1242 /$ dev.121939 
Weir, L., Chen, D., Pastore, C., Isner, J. M., and Walsh, K. (1995). Expression of gax, a growth arrest homeobox gene, is rapidly down-regulated in the rat carotid artery during the proliferative response to balloon injury. J. Biol. Chem. 270, 5457-5461. doi: 10.1074/jbc. 270.10 .5457

Wilkinson, J. H., Hopewell, J. W., and Reinhold, H. S. (1981). A quantitative study of age-related changes in the vascular architecture of the rat cerebral cortex. Neuropathol. Appl. Neurobiol. 7, 451-462. doi: 10.1111/j.1365-2990. 1981.tb00245.x

Won, C., Lin, Z., Kumar, P. T., Li, S., Ding, L., Elkhal, A., et al. (2013). Autonomous vascular networks synchronize GABA neuron migration in the embryonic forebrain. Nat. Commun. 4:2149. doi: 10.1038/ ncomms 3149

Wu, Z., Guo, H., Chow, N., Sallstrom, J., Bell, R. D., Deane, R., et al. (2005). Role of the MEOX2 homeobox gene in neurovascular dysfunction in Alzheimer disease. Nat. Med. 11, 959-965. doi: 10.1038/nm1287

Yang, H., Xie, Z., Wei, L., Yang, H., Yang, S., Zhu, Z., et al. (2013). Human umbilical cord mesenchymal stem cell-derived neuron-like cells rescue memory deficits and reduce amyloid- $\beta$ deposition in an AßPP/PS1 transgenic mouse model. Stem Cell Res. Ther. 4:76. doi: 10. $1186 /$ scrt227

Yuen, T. J., Silbereis, J. C., Griveau, A., Chang, S. M., Daneman, R., Fancy, S. P. J., et al. (2014). Oligodendrocyte-encoded HIF function couples postnatal myelination and white matter angiogenesis. Cell 158, 383-396. doi: 10.1016/j. cell.2014.04.052

Yun, H. M., Kim, H. S., Park, K. R., Shin, J. M., Kang, A. R., Il Lee, K., et al. (2013). Placenta-derived mesenchymal stem cells improve memory dysfunction in an A 1-42-infused mouse model of Alzheimer's disease. Cell Death Dis. 4:e958. doi: $10.1038 /$ cddis. 2013.490
Zhang, Y., Chen, K., Sloan, S. A., Bennett, M. L., Scholze, A. R., O'Keeffe, S., et al. (2014). An RNA-sequencing transcriptome and splicing database of glia, neurons, and vascular cells of the cerebral cortex. J. Neurosci. 34, 11929-11947. doi: 10.1523/JNEUROSCI.1860-14.2014

Zhou, Y., and Nathans, J. (2014). Gpr124 controls CNS angiogenesis and blood-brain barrier integrity by promoting ligand-specific canonical WNT signaling. Dev. Cell 31, 248-256. doi: 10.1016/j.devcel.2014. 08.018

Zlokovic, B. V. (2008). The blood-brain barrier in health and chronic neurodegenerative disorders. Neuron 57, 178-201. doi: 10.1016/j.neuron.2008. 01.003

Zlokovic, B. V. (2011). Neurovascular pathways to neurodegeneration in Alzheimer's disease and other disorders. Nat. Rev. Neurosci. 12, 723-738. doi: $10.1038 / \mathrm{nrn} 3114$

Conflict of Interest: TI, HK, KS, and $\mathrm{YH}$ were employed by the Rohto Pharmaceutical Company Limited.

The remaining authors declare that the research was conducted in the absence of any commercial or financial relationships that could be construed as a potential conflict of interest.

Copyright (C) 2020 Watanabe, Imaizumi, Kawai, Suda, Honma, Ichihashi, Ema and Mizutani. This is an open-access article distributed under the terms of the Creative Commons Attribution License (CC BY). The use, distribution or reproduction in other forums is permitted, provided the original author(s) and the copyright owner(s) are credited and that the original publication in this journal is cited, in accordance with accepted academic practice. No use, distribution or reproduction is permitted which does not comply with these terms. 